\title{
UPAYA PENINGKATAN PRODUKTIVITAS DAN KEUNTUNGAN HASIL TANGKAP DENGAN MENGUBAH NELAYAN BURUH MENJADI NELAYAN PEMILIK
}

\author{
Yuliana Anastasia Ngamel ${ }^{1}$, Wellem Anselmus Teniwut ${ }^{2}$
}

\begin{abstract}
ABSTRAK
Membangun dari daerah merupakan program utama dari pemerintahan Presiden Joko Widodo, maka program Ipteks Bagi Masyarakat (IbM) ini bertujuan untuk mendukung program pemerintah dengan meningkatkan produktivitas dan perekonomian nelayan tangkap di Dusun Duroa, Kota Tua, Provinsi Maluku dengan mengkonversi status mereka dari nelayan tangkap buruh menjadi nelayan pemilik dan memberikan modal, pelatihan, penyuluhan serta pendampingan. Program ini penting sebagai inisiasi untuk meningkatkan perekonomian nelayan tangkap Dusun Duroa yang sebagian besar nelayan tangkap yang berada di wilayah ini merupakan nelayan buruh. Hasil dari program ini sudah terlihat dampaknya dimana keuntungan nelayan tangkap meningkat sangat signifikan karena hasil yang didapatkan seluruhnya masuk ke nelayan tangkap dan produktivitasnya juga meningkat dengan teknik tangkap yang sesuai dengan perairan di sekitar wilayah desa Durua.
\end{abstract}

Kata Kunci: IbM, Pengabdian, Nelayan Tangkap, Produktivitas.

\begin{abstract}
Main focus of President Joko Widodo is to build from rural area. In order to support this program, we conducted community service program ( $\mathrm{IbM})$ with grant from ministry of higher education to increase the productivity and economic level of fishermen in Duroa Village, Tual City, Maluku Province by converting their status from fishing worker into fishing owner. This program is important as initiation step to improve the economic prosperity of fishermen in the area since most of fishermen are fishing workers who work for the owner. Result of this program have showed immediate impact for fishermen partner of this program, where there is significant increase on the income because all revenue are theirs and no need to share it with fishing owner as before. We help to enhance their ability on fishing by training, counselling and mentoring of proper fishing technique suitable with water around Duroa Village.
\end{abstract}

Keywords: IbM, Community Service, Fishermen, Productivity.

\section{PENDAHULUAN}

Kota Tual secara khusus, salah produsen ikan utama wilayah ini adalah Desa Dullah Laut yang secara administratif masuk dalam wilayah Kecamatan Dullah Utara dan terdiri atas dua wilayah yaitu Desa Dullah Laut dan Dusun Duroa (baca, Dusun Dullah Laut dalam bahasa daerah). memiliki potensi perairan yang kaya akan potensi sumber daya ikan, dimana jenis-jenis ikan

\footnotetext{
${ }^{1}$ Program Studi Teknologi Penangkapan Ikan, Politeknik Perikanan Negeri Tual, ngamelrahaded@yahoo.com

2 Program Studi Agribisnis Perikanan, Politeknik Perikanan Negeri Tual, wateniwut@polikant.ac.id
} 
demersal yang memiliki nilai ekonomis yang tinggi seperti ikan kerapu, Ikan Kakatua, Ikan Merah, Ikan Biji Nangka, Ikan Ekor Kuning. Hasil survey awal di lapangan oleh tim pengabdi menunjukkan bahwa ikan yang biasanya berasal dari Desa dan Dusun Dullah Laut memiliki image yang baik di mata masyarakat Tual dan sekitarnya.

Dari hasil pengamatan langsung di lapangan menunjukkan bahwa hanya kurang dari seperempat nelayan Dusun Duroa yang memiliki alat tangkap lengkap yang juga bertindak sebagai nelayan pemilik bagi nelayan lainnya yang belum memiliki kemampuan modal dan peralatan yang diperlukan, menurut Husodo, (2004) kondisi ini disebut dengan buruh tani, dimana para petani atau dalam hal ini nelayan bekerja menggunakan peralatan dari pemilik modal untuk berusahan dengan syarat pembagian hasil dilakukan secara bersama. Hasil pengamatan juga menunjukkan bahwa para nelayan pemilik juga merupakan warga Dusun yang telah memiliki tingkat pendapatan dan sumber penghasilan lain selain dari hasil tangkap, sedangkan nelayan buruh yang lain hanya menggantungkan seluruh kegiatan pemenuhan kebutuhan sehari-hari melalui kegiatan perikanan tangkap.

Hasil tangkapan oleh nelayan buruh tidak dapat langsung dijual kepada konsumen akhir atau kepada penadah pasar sebelum akhirnya dijual kepada konsumen akhir karena selain memerlukan biaya dalam pengiriman dan penjualan juga karena nelayan buruh diharuskan menjual kepada nelayan pemilik. Kondisi ini tentu saja akan sangat berpengaruh terhadap harga dan keuntungan termasuk dampak ekonomis yang akan dirasakan oleh nelayan buruh yang ada, Kotler dan Keller (2006) mengemukakan bahwa saluran pemasaran yang efektif adalah yang memberikan nilai ekonomis yang optimum. Kondisi empiris di lapangan ditemukan bahwa harga ikan yang dibayarkan oleh nelayan pemilik kepada nelayan buruh adalah sebesar Rp.15.000/Tali hingga sampai ke tangan konsumen di pasar bisa mencapai Rp.30.000,- Rp. $35.000,-$

Para nelayan buruh yang ada di Dusun Duroa termasuk kedua mitra juga masih melakukan usaha secara individu dengan jadwal yang tidak tentu setiap harinya sehingga jumlah tangkapan akan sangat berfluktuasi yang dengan sendirinya akan berbanding lurus dengan pendapatan yang diterima. Sehingga kegiatan IbM ini berorientasi untuk meningkatkan produktivitas baik dalam kuantitas maupun kualitas sekaligus meningkatkan dapat ekonomis yang lebih baik kepada para nelayan yang ada di Dusun Duroa, sehingga potensi perairan yang besar ini juga dapat dinikmati secara ekonomis bukan hanya oleh nelayan di Desa Dullah Laut tetapi juga di Dusun Duroa.

Dari hasil survey awal yang telah dilakukan oleh tim pengabdian ini diperoleh informasiinformasi yang menjadi permasalahan dari kedua mitra, yang pertama dari sisi produktivitas adalah:

1. Bagaimana menjadikan nelayan buruh yang ada untuk menjadi nelayan pemilik, sehingga waktu dan kuantitas kegiatan pengakapan tidak tergantung dengan nelayan pemilik, sehingga tingkat produktivitas dapat meningkat?

2. Alat dan metode penangkapan yang seperti apa yang dapat digunakan untuk meningkatkan jumlah tangkapan pada jenis ikan yang memiliki tingkat ekonomis yang baik? 
3. Bagaimana cara mengelola sebuah usaha penangkapan yang berkelanjutan dan memiliki tingkat keuntungan yang baik juga terkait bagaimana membangun jiwa wirausaha dari kedua mitra?

\section{METODE PEMECAHAN MASALAH}

Karakteristik dan masalah nelayan adalah: tingkat pengetahuannya tentang manfaat sumber daya pantai dan laut rendah, usaha tergantung musim, hasil tangkapan cenderung menurun, alat tangkap yang digunakan sangat sederhana dan sifat komoditas yang dihasilkan adalah perishable sedangkan pengolahan pada umumnya kurang atau tidak dilakukan (Alfian, et al 2014). Modal yang terbatas baik dalam bentuk uang dan peralatan juga menjadi masalah klasik yang selalu dihadapi oleh nelayan yang berada di wilayah pesisir yang jauh dari kota besar. Maka beberapa pendekatan yang digunakan dalam kegiatan pengabdian ini antara lain adalah sebagai berikut:

a. Penyuluhan

Kegiatan penyuluhan dilakukan untuk memberikan gambaran mengenai IPTEKS yang akan ditransfer kepada kedua mitra akan dilakukan secara serentak bagi kedua mitra dikarenakan hanya berupa konsep sehingga masih dapat secara efektif jika dilakukan secara bersama-sama bagi kedua mitra. Penyuluhan penting untuk memberikan pemahaman awal mengenai IPTEKS termasuk bagi permasalahan yang dihadapi dari sisi produksi maupun manajemen, yang kemudian akan ditajamkan melalui metode pendekatan selanjutnya yaitu pelatihan dan demonstrasi.

b. Pelatihan

Setelah dilakukan penyuluhan maka akan ditindaklanjuti dengan kegiatan pelatihan dan demonstrasi. Kedua pendekatan ini penting dikarenakan pertimbangan kompetensi dan perimbangan intensitas permasalahan yang dihadapi oleh kedua mitra ini merupakan permasalahan yang memerlukan adanya latihan dan praktik untuk dapat dijalankan secara baik di lapangan. Sehingga untuk permasalahan baik dari sisi produktif maupun manajemen akan dilakukan pelatihan dan demonstrasi contohnya seperti proses pembuatan pembukuan sederhana dikarenakan kompetensi yang dimiliki mitra maka kegiatan penyuluhan akan kurang efektif jika tidak ditindaklanjuti dengan pelatihan dan demonstrasi mengenai cara pembuatan, pengisian, kapan dilakukan dan lainnya.

c. Pendampingan

Selain memberikan penyuluhan, pelatihan dan demonstrasi maka, untuk memastikan bahwa para mitra dapat melakukan usaha dan manajemen perikanan tangap yang memberikan dampak ekonomi yang baik maka perlu adanya pendampingan. Sehingga diharapkan kegiatan pengabdian yang dilakukan ini benar-benar memberikan dampak yang positif bagi mitra dan juga agar kedua mitra agar lebih fokus dan terarah dalam melakukan kegiatan usaha perikanan tangkap ini, karena kedua mitra akan dengan sangat mudah mengajukan pertanyaan dan tim pengabdi juga dapat memonitor permasalahan yang dihadapi oleh kedua mitra agar secara cepat dan tanggap permasalahan yang mungkin akan dialami oleh mitra dalam kegiatan pengabdian ini. Diharapkan program pengabdian ini dapat berjalan dengan baik. 
Tabel 1. Rancangan Justifikasi Solusi Pengusul Bersama Mitra

\begin{tabular}{|c|c|c|c|}
\hline \multicolumn{4}{|c|}{ 1. Sisi Produksi } \\
\hline No & Permasahalan & $\begin{array}{l}\text { Justifikasi Solusi Bersama } \\
\text { Mitra }\end{array}$ & Keterlibatan Mitra \\
\hline 1 & $\begin{array}{l}\text { Menjadikan nelayan } \\
\text { buruh yang ada untuk } \\
\text { menjadi nelayan } \\
\text { pemilik }\end{array}$ & $\begin{array}{l}\text { Memberikan bantuan } \\
\text { peralatan dan perlengkapan } \\
\text { untuk usaha perikanan } \\
\text { tangkap }\end{array}$ & $\begin{array}{l}\text { Kedua mitra dilibatkan dalam } \\
\text { proses pembelian, pengiriman } \\
\text { hingga proses pemasangan dan } \\
\text { penggunaan perlengkapan dan } \\
\text { peralatan yang akan diberikan }\end{array}$ \\
\hline 2 & $\begin{array}{l}\text { Alat dan metode } \\
\text { penangkapan yang } \\
\text { sesuai }\end{array}$ & $\begin{array}{l}\text { Memilih alat tangkap yang } \\
\text { baik, kuat dan sesuai dengan } \\
\text { kebutuhan mitra dalam } \\
\text { melakukan usaha perikanan } \\
\text { tangkap }\end{array}$ & $\begin{array}{l}\text { Kedua mitra ikut terlihat dalam } \\
\text { memberikan masukan dalam } \\
\text { proses pembelian alat tangkap } \\
\text { mengenai jenis dan jumlah } \\
\text { sehingga alat tangkap yang } \\
\text { dibeli sesuai dengan apa yang } \\
\text { dibutuhkan oleh kedua mitra }\end{array}$ \\
\hline \multicolumn{4}{|c|}{ 2. Sisi Manajemen } \\
\hline No & Permasalahan & $\begin{array}{l}\text { Justifikasi Solusi Bersama } \\
\text { Mitra }\end{array}$ & Keterlibatan Mitra \\
\hline 1 & $\begin{array}{l}\text { Mengelola sebuah } \\
\text { usaha penangkapan } \\
\text { yang berkelanjutan }\end{array}$ & $\begin{array}{l}\text { Mitra akan diberikan } \\
\text { pengetahuan bagaimana } \\
\text { mengeloa sebuah usaha dan } \\
\text { bagaimana membangun jiwa } \\
\text { wirausaha yang baik }\end{array}$ & $\begin{array}{l}\text { Kedua mitra akan memberikan } \\
\text { dukungan, waktu dan tempat } \\
\text { untuk menerima pengetahuan } \\
\text { mengenai bagaiman mengelola } \\
\text { usaha perikanan tangkap yang } \\
\text { baik termasuk membangun jiwa } \\
\text { wirausaha yang baik }\end{array}$ \\
\hline
\end{tabular}

\section{HASIL DAN PEMBAHASAN}

\subsection{Menjadikan nelayan buruh yang ada untuk menjadi nelayan pemilik}

Dalam kegiatan IbM Nelayan Dusun Duroa ini, hasil yang dicapai adalah kedua mitra yaitu Bapak Gerardus dan Bapak Hironimus, masing-masing telah mendapatkan 1 buah mesin ketinting merek Honda tipe Honda GX 160, 5.5 HP. Selain mesin ketinting sebagai tenaga penggerak dalam melakukan operasi penangkapan ikan, kedua mitra juga telah memiliki body perahu sebagai kapal penangkapan ikan. Bapak Gerardus memiliki body perahu dari fiber dengan ukuran 6,5 x 1 x 0,8 m, sedangkan Bapak Hironimus memiliki body perahu dari fiber dengan ukuran $5 \times 1 \times 0,5 \mathrm{~m}$. Kedua mitra juga telah diberikan alat pancing yang sesuai berupa pancing rawai dengan rangkaian bahan-bahannya yaitu mata kail (hook) nomor 8 dan 9, tali senar (monofilament), pemberat (sinker) berbentuk kerucut, pelampung (float) dan kili-kili (swivel). 


\subsection{Alat dan metode penangkapan untuk meningkatkan produktivitas}

Perairan sekitar Dusun Duroa masuk dalam kategori kedalaman laut menengah dengan dasar lain pasir dan terdapat banyak lamun sehingga terdapat banyak ikan demersal, sehingga teknik tangkap yang sesuai adalah pancing tonda dan pancing dasar.
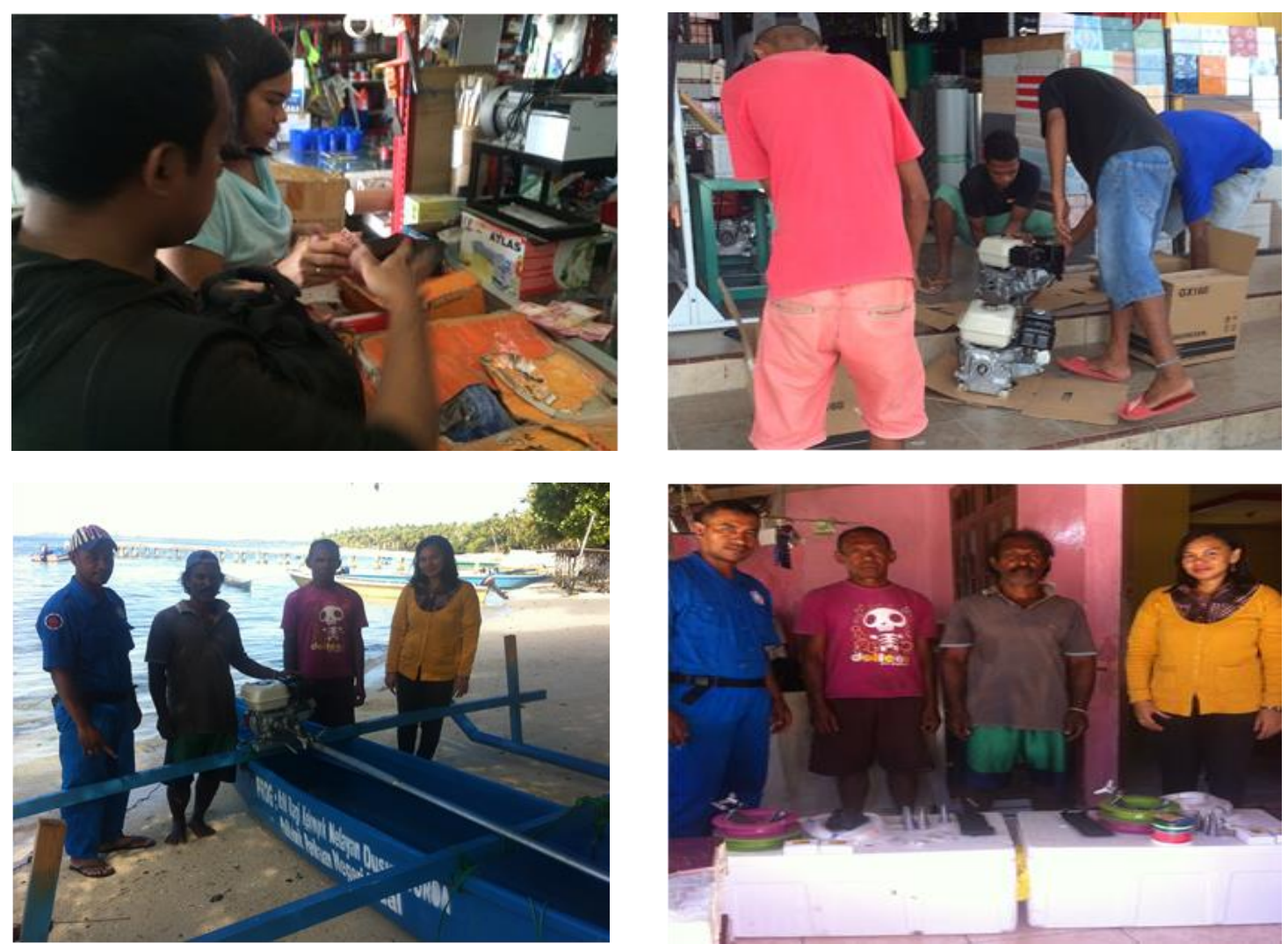

Gamhar 1 Pemhelian dan Penverakan Modal I Jcaha

1. Teknik Pancing Tonda

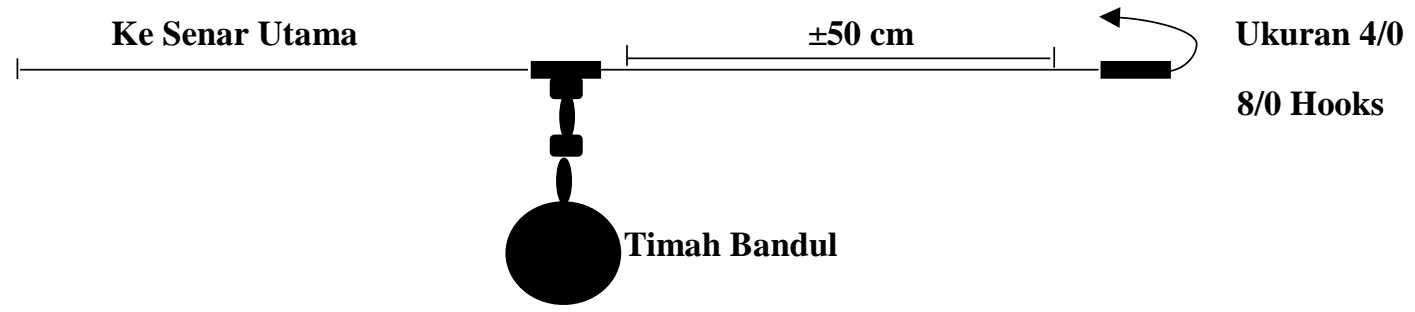

Gambar 2. Perambut Batu Mati

2. Teknik Pancing Dasar

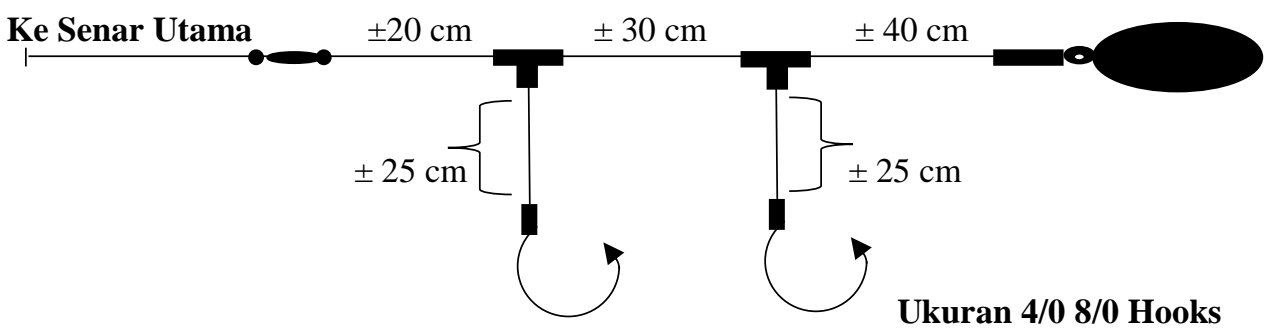

Gambar 3. Teknik Pancingan Dasar Dengan Penggunaan Batu Mati Dengan Mata Ganda 


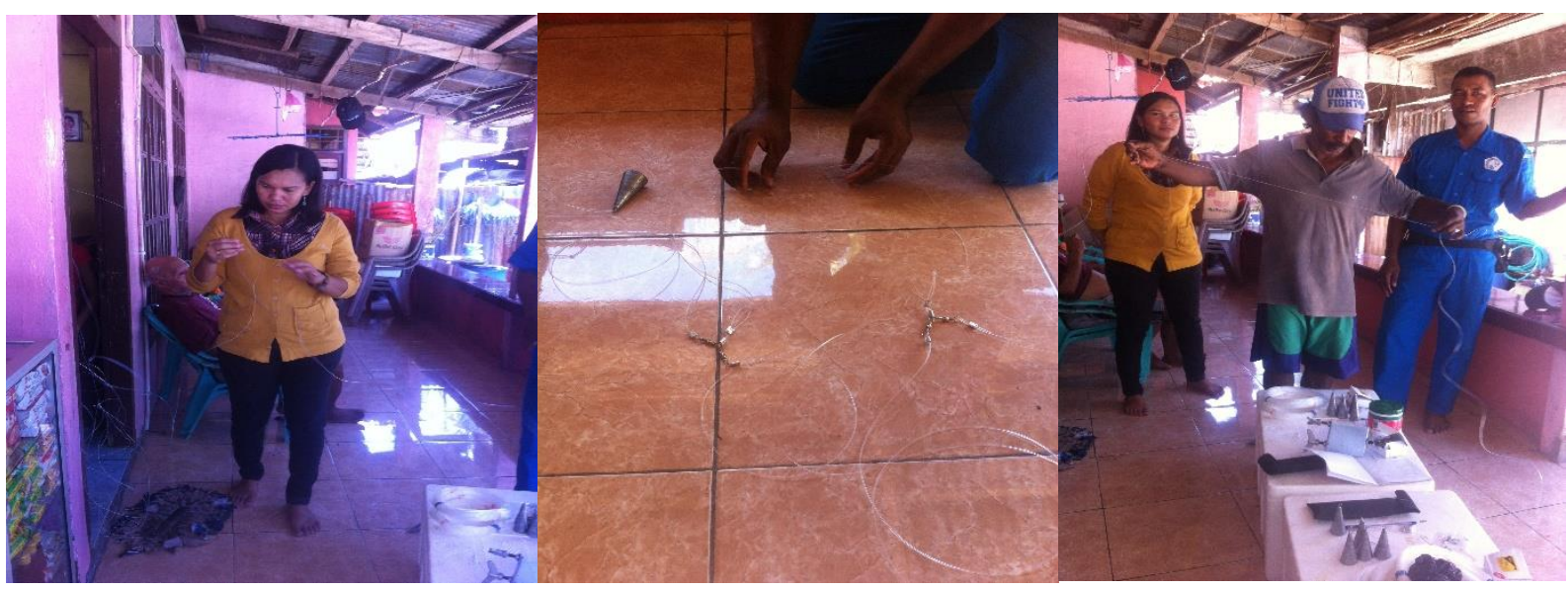

Gambar 4. Pelatihan dan Demonstrasi Metode Penangkapan Ikan

\subsection{Mengelola sebuah usaha penangkapan yang berkelanjutan}

Kedua mitra telah diberikan pelatihan mengenai cara manajemen atau mengatur waktu melakukan operasi penangkapan ikan menggunakan pancing. Selain mengatur waktu operasi penangkapan, kedua mitra juga telah mengetahui cara mengatur waktu untuk perawatan alat tangkap dan kapal penangkap/perahu. Pelatihan juga termasuk dengan memilih saluran pemasaran yang efektif dan menguntungkan dengan tidak melalui perantara yang panjang tetapi langsung dijual ke pasar tradisonal yang ada sehingga hasil pendapatan yang diperoleh dapat lebih maksimal dan memberikan dampak ekonomi yang lebih besar. Pembukuan juga diberikan sehingga para mitra dalam mengontrol pengeluaran dan penerimaan sehingga usaha ini dapat berkelanjutan.

\section{SIMPULAN DAN SARAN}

Melalui kegiatan IbM ini adalah kedua mitra telah menggunakan body perahu / kapal penangkap ikan, mesin ketinting dan alat tangkap pancing yang telah mereka miliki masingmasing untuk operasi penangkapan ikan. Hasil tangkapan mitra meningkat menjadi $20 \%$ dari hasil tangkapan sebelumnya. Selain itu kedua mitra juga telah memiliki jadwal untuk melakukan operasi penangkapan ikan dan jadwal untuk merawat body perahu, mesin serta alat tangkap yang telah mereka miliki. Program ini masuk dalam kategori skala kecil namun telah memberikan hasil nyata sehingga diharapkan menjadi inisiasi awal bagi pemerintah daerah dalam menggerakan perekonomian daerah pesisir dengan mengonversi nelayan buruh menjadi nelayan pemilik.

\section{DAFTAR PUSTAKA}

Alfian, Martoyo dan E.I Listiani, 2041, Implementasi Program Bantuan Perikanan Tangkap Di Kecamatan Pemangkat Kabupaten Sambas, Jurnal Tesis PMIS-UNTAN-PSIAN2014.

Husodo, S.Y., 2004, Pertanian Mandiri, Jakarta : Penerbar Swadaya.

Kotler. P dan K.L Keller, 2006, Manajemen Pemasaran Jilid 1, Terjemahan, Indeks ; Jakarta. 